\title{
A presença e o lugar de professores negros e negras no IFMT: ações afirmativas,
}

\section{avanços e desafios}

The presence and the place of black teachers at IFMT: affirmative actions, advances and challenges

La presencia y el lugar de los docentes negros y negras en el IFMT: acciones afirmativas, avances y

desafíos

Recebido: 08/12/2021 | Revisado: 12/12/2021 | Aceito: 15/12/2021 | Publicado: 20/12/2021

\author{
Josadaque Martins Silva \\ ORCID: https://orcid.org/0000-0001-9739-5616 \\ Instituto Federal de Educação, Ciência e Tecnologia de Mato Grosso, Brasil \\ E-mail: josadaquemartins@usp.br \\ Thiago Beirigo Lopes \\ ORCID: https://orcid.org/0000-0002-9409-6140 \\ Instituto Federal de Educação, Ciência e Tecnologia de Mato Grosso, Brasil \\ E-mail: thiago.lopes@ifmt.edu.br \\ Cristiane da Silva Ferreira \\ ORCID: https://orcid.org/0000-0002-8624-5521 \\ Instituto Federal de Educação, Ciência e Tecnologia de Mato Grosso, Brasil \\ E-mail: cristiane.ferreira@ifmt.edu.br
}

\begin{abstract}
Resumo
Este artigo é resultado do projeto de pesquisa 'Educação e ações afirmativas: um estudo sobre a presença e o lugar de professores negros e negras no IFMT', desenvolvido no Instituto Federal de Educação, Ciência e Tecnologia de Mato Grosso. Tem por objetivo analisar, a partir de uma pesquisa quantitativa, a presença e o lugar de docentes negros e negras na estrutura educacional e administrativa do IFMT. Problematizamos especificamente esta instituição, de modo a compreender o locus dela no cenário de implementação de políticas de ações afirmativas no Brasil pós Durban (2001), tendo em vista que, no contexto geral das universidades públicas e privadas brasileiras, é visível a diminuta presença de professores negros e negras na estrutura didática e administrativa dessas academias. Para tanto, a pesquisa parte do pressuposto de que o cerne deste problema é o racismo acadêmico, justificado 'brasileiristicamente' pelo mito da democracia racial, presente na obra de Gilberto Freyre (2003). Por outro lado, descontruímos a ideia de democracia racial, principal impeditivo para a discussão de políticas de ações afirmativas no Brasil até 2001, ano da Terceira Conferência de Durban, tendo como aporte teórico Florestan Fernandes (1972), Kabengele Munanga (1999, 2014), José Jorge de Carvalho $(2003,2006)$ e Nilma Lino Gomes (2005). Resulta da investigação que o combate à desigualdade racial na docência superior e nas instâncias administrativas universitárias requer novas medidas de ações afirmativas que promovam a igualdade racial e, por conseguinte, ampliem a presença e o protagonismo de docentes negros e negras no ambiente acadêmico.
\end{abstract}

Palavras-chave: Ações afirmativas; Racismo acadêmico; Professor negro; Ensino.

\begin{abstract}
This article is the result of the research Project "Education and affirmative action: a study on the presence and place of black teachers at IFMT" developed at the Federal Institute of Education, Science and Technology of Mato Grosso. It aims to analyze, from a quantitative research the presence and place of black teachers in the IFMT educational and administrative structure. We specifically problematize this institution, in order to understand its locus in the scenario of implementation of affirmative action policies in Brazil after Durban (2001), considering that in the general context of public and private Brazilian universities it`s visible the small presence of black men and women professors in the didact and administrative structure of these academies. Therefore, the research assumes that the core of this problem is academic racism, justified by the myth of racial democracy, present in the work of Gilberto Freyre (2003). On the other hand, we deconstructed the idea of racial democracy, the main impediment to discussion of affirmative action policies in Brazil until 2001, the year of the Third Conference of Durban, having as theoretical support Florestan Fernandes (1972), Kabengele Munanga (1999, 2014), José Jorge de Carvalho (2003, 2006) and Nilma Lino Gomes (2005). It results from the investigation that combating racial inequality in higher education and university administrative instances requires new affirmative action measures that promote racial equality and, therefore, expand the presence and prominence of black professors in the academic environment.
\end{abstract}

Keywords: Affirmative actions; Academic racism; Black professor; Teaching. 


\begin{abstract}
Resumen
Este artículo es el resultado del proyecto de investigación 'Educación y acción afirmativa: un estudio sobre la presencia y lugar de los docentes negros y negras en el IFMT', desarrollado en el Instituto Federal de Educación, Ciencia y Tecnología de Mato Grosso. Tiene como objetivo analizar, a partir de una investigación cuantitativa, la presencia y lugar de los docentes negros y negras en la estructura educativa y administrativa del IFMT. Específicamente problematizamos esta institución, para entender su locus en el escenario de implementación de políticas de acción afirmativa en Brasil después de Durban (2001), considerando que, en el contexto general de las universidades públicas y privadas brasileñas, se percibe la escasa presencia de profesores negros y negras en la estructura didáctica y administrativa de estas academias. Por tanto, la investigación asume que el núcleo de este problema es el racismo académico, justificado por el mito de la democracia racial, presente en el trabajo de Gilberto Freyre (2003). Por otro lado, deconstruimos la idea de democracia racial, principal impedimento para la discusión de las políticas de acción afirmativa en Brasil hasta 2001, año de la Tercera Conferencia de Durban, teniendo como soporte teórico a Florestan Fernandes (1972), Kabengele Munanga (1999, 2014), José Jorge de Carvalho (2003, 2006) y Nilma Lino Gomes (2005). Resulta de la investigación que combatir la desigualdad racial en la educación superior y las instancias administrativas universitarias requiere nuevas medidas de acción afirmativa que promuevan la igualdad racial y, por tanto, amplíen la presencia y protagonismo de los profesores negros y negras en el ámbito académico.
\end{abstract}

Palabras clave: Acciones afirmativas; Racismo académico; Profesor negro; Enseñanza.

\title{
1. Introdução
}

Este artigo é resultado do projeto de pesquisa 'Educação e ações afirmativas: um estudo sobre a presença e o lugar de professores negros e negras no IFMT', desenvolvido no Instituto Federal de Educação, Ciência e Tecnologia de Mato Grosso.

Tem como objetivo analisar, por meio de uma pesquisa quantitativa, a presença e o lugar de docentes negros e negras na estrutura educacional e administrativa do IFMT. Primeiramente, analisamos a situação dos professores negros e negras na estrutura geral didática e administrativa racista das universidades públicas e privadas no Brasil pós Durban (2001), portanto, após a implementação de políticas de ações afirmativas no contexto brasileiro. Em seguida, descrevemos o caso específico dos docentes negros e negras no IFMT, ressaltando os avanços e os desafios da política de ações afirmativas nessa instituição.

\section{Metodologia}

Em termos metodológicos, o estudo pauta-se na pesquisa quantitativa e bibliográfica. O projeto de pesquisa foi desenvolvido no período de agosto de 2016 a julho de 2017, com o auxílio financeiro ao pesquisador concedido pelo IFMT e bolsa do Programa Institucional de Bolsas de Iniciação Científica para o Ensino Médio do Conselho Nacional de Desenvolvimento Científico e Tecnológico (PIBIC-EM/CNPq).

Para a verificação do quantitativo da presença de professores negros e negras na estrutura educacional e administrativa do IFMT foi realizada uma pesquisa por meio de um questionário. A lista de professores utilizada para o controle, envio e recebimento dos questionários foi a lista dos professores efetivos aptos a votarem na eleição para gestores da reitoria e seus campi em novembro de 2016. Tal lista foi divulgada em setembro do mesmo ano. A escolha dessa lista se deu por ter sido atualizada para esse evento democrático de escolha dos gestores e assim alcançar a maior quantidade possível de servidores. Havia 719 professores na lista, no entanto, foram enviadas com sucesso 648 mensagens por correio eletrônico. As demais 71 retornaram erro no envio devido à inexistência do endereço de correio eletrônico.

A ferramenta escolhida para ser utilizada como questionário foi o Formulários Google, que apesar do título de formulário é um questionário digital em que cada participante da pesquisa o recebeu em seu endereço eletrônico institucional. Vieira (2009) esclarece que o questionário é um instrumento de pesquisa composto por questões sequenciadas que versam sobre algum tema específico. Também indica que esse instrumento é apresentado aos participantes da pesquisa para que respondam às questões e devolvam o questionário preenchido ao pesquisador, que pode transformá-las em respostas estatísticas (Vieira, 2009).

O questionário utilizado foi composto, majoritariamente, por questões fechadas, que são apresentadas por Marconi e Lakatos (2002) como aquelas em que o pesquisado escolhe sua resposta entre duas ou mais opções, podendo ser de múltipla 
escolha com uma série de possíveis respostas, abrangendo várias facetas do mesmo assunto. Ainda, Sampieri, Collado e Lucio (2013) apresentam as perguntas fechadas como constituídas por categorias ou opções de respostas previamente delimitadas e indicam que pode haver mais de uma possibilidade de resposta.

Diante disso, o questionário utilizado foi composto pelas seguintes questões:

1. Nome Completo:

2. Sexo: (_) Masculino /(_) Feminino.

3. Cor/Raça: (_) Amarelo /(_) Branco /(_) Indígena /(_) Pardo /(_) Preto.

4. Qual foi a forma de ingresso no IFMT? (_) Concurso público/Vaga para ampla concorrência / (_) Concurso público/Vaga reservada para negros /(_) Outros:

5. Além da docência, ocupa cargo de Função Gratificada (FG) ou Cargo de Direção (CD)? (_) Sim /(_) Não

6. Se no item anterior a resposta foi SIM, qual o cargo que ocupa?

7. Qual a maior titulação que possui? (_) Graduação /(_) Especialização / (_) Mestrado /(_) Doutorado /(_) PósDoutorado.

Conforme Marconi e Lakatos (2002), o questionário necessita ser limitado em extensão e em finalidade. Mesmo porque, se for muito extenso, pode ocasionar fadiga e desinteresse ou se curto demais pode ter o risco de não obter informações suficientes. Ainda segundo as autoras, o questionário obtém respostas que materialmente seriam inacessíveis (Marconi, Lakatos, 2002).

Em posse da lista, o questionário on-line foi enviado para cada um dos endereços eletrônicos institucionais dos professores listados. Sendo o questionário integrante à mensagem enviada e respondido no próprio corpo dela, depois clicando em enviar.

Foram enviadas remessas de mensagens em três momentos: o primeiro e o segundo, respectivamente, em setembro e novembro de 2016 e o terceiro em janeiro de 2017. Para não ficar o envio de mensagens inoportuno, principalmente aos que já responderam, os nomes dos que respondiam eram retirados dos envios posteriores. Não havendo assim envio duplo para alguém que já tenha respondido. Para evitar a repetição de indivíduos pesquisados, os resultados eram rotineiramente analisados quanto ao nome e endereço eletrônico dos que respondiam.

Para apresentação dos dados produzidos, os mesmos foram tratados estatisticamente por meio de tabelas e gráficos, em que foram verificados os estratos gerais da instituição e seus campi, campi Avançados e Centros de Referência.

\section{Resultados e Discussão}

O debate sobre a presença e o lugar subalterno de docentes negros e negras na docência superior tem mobilizado muitos historiadores da educação, sociólogos e antropólogos no Brasil e impulsionado novos estudos. Tais pesquisadores têm mostrado a importância de se buscar e entender a razão disso. Sendo assim, identificamos as obras publicadas que tratam do assunto, e realizamos uma pesquisa no portal de periódicos da CAPES, buscando artigos, dissertações e teses que foram publicados a partir de 2001, período pós Durban, que analisam o tema da presença de professores negros e negras no magistério superior brasileiro.

Nesse levantamento, notamos que os primeiros estudos pós Durban (2001) sobre esta temática enfatizavam mais a ausência de discentes negros e negras no ambiente universitário, mostrando a necessidade de cotas para o ingresso desses estudantes na graduação. Porém, alguns importantes pesquisadores, como Maria Solange Pereira Ribeiro (2001), José Jorge de Carvalho, Nilma Lino Gomes, dentre outros, passaram a enfocar o problema do docente negro, ratificando que, temos ainda, no contexto geral da academia brasileira, um racismo acadêmico arraigado, cuja consequência é a ínfima presença de docentes 
negros e negras nas universidades públicas. Ademais, eles constatam que a maioria desses docentes se encontram num lugar de subalternidade nessas instituições.

Consoante a problemática suscitada, o objetivo do presente estudo foi expor a relevância da Terceira Conferência Mundial de Durban (2001) na discussão sobre a formulação e implementação de políticas públicas e ações afirmativas no Brasil. Descrever o mito da democracia racial como cerne embasador das desigualdades raciais no contexto brasileiro e, mormente, o principal impeditivo no processo de implementação de políticas de ações afirmativas. Mostrar que, a despeito dos avanços nos últimos dez anos, como a efetivação da lei de cotas, ainda é perceptível um problema na estrutura educacional do Brasil, a saber: a quase ausência de professores negros e negras nas universidades públicas brasileiras. Apontar que o enfrentamento desse problema requer a ampliação de ações afirmativas no mundo acadêmico, que viabilize a formação e a inserção de novos docentes negros e negras nos quadros da universidade pública. E, por fim, apresentar os resultados e a discussão da pesquisa quantitativa sobre a presença e o lugar de professores negros e negras no IFMT.

\subsection{A Declaração de Durban (2001): Estado, educação para as relações étnico-raciais e ações afirmativas}

Em 2001, de 31 de agosto a 8 de setembro, na cidade de Durban, África do Sul, vários países, dentre eles o Brasil, se reuniram para a realização da Terceira Conferência Mundial contra o Racismo, Discriminação Racial, Xenofobia e Formas Conexas de Intolerância, organizada pela UNESCO. O cerne da Conferência de Durban foi debater o efetivo compromisso dos Estados na implementação de políticas públicas e ações afirmativas para a eliminação de todas as formas de racismo, discriminação e desigualdade racial (Declaração de Durban, 2001).

Observa-se que a Declaração de Durban (2001), em relação aos africanos e afrodescendentes, insta os Estados a facilitarem o acesso e a participação destas pessoas em todos os aspectos políticos, econômicos, sociais e culturais da sociedade, objetivando o enfrentamento das desigualdades raciais no âmbito da educação, saúde, cultura, esporte e lazer, segurança, trabalho e moradia.

E no plano específico da educação, a Declaração de Durban (2001) insta os Estados a implementarem medidas de ações afirmativas, assegurando e promovendo o acesso à educação e a novas tecnologias que ofereçam aos africanos e afrodescendentes, em particular, a mulheres e crianças, recursos adequados à educação, ao desenvolvimento tecnológico e ao ensino a distância em comunidades locais. E mais, insta os Estados a promoverem a plena e exata inclusão da história e da contribuição dos africanos e afrodescendentes no currículo educacional ${ }^{1}$ (Declaração de Durban, 2001).

Entretanto, até o ano de 2001, a discussão sobre o racismo e as desigualdades raciais e, mormente, a implementação de políticas e programas de ações afirmativas por parte do Estado foi ínfima no Brasil, excetuando os raros acadêmicos que pesquisam o tema. Para tanto, se faz cogente buscar a razão principal desse silêncio acadêmico.

\subsection{Ações afirmativas e o mito da democracia racial}

O Brasil é um país multicultural, porém marcado pelo racismo e desigualdade racial. Ora, nega-se essa realidade racista, corroborando a ideia de democracia racial. Ou seja, diferentemente da experiência social estadunidense e sul-africana, historicamente, abalizada na segregação racial, teorizou-se, mormente, o sociólogo Gilberto Freyre, em seu livro Casa-grande \& senzala, que se formou, no contexto da América tropical, "uma sociedade agrária na estrutura, escravocrata na técnica da exploração econômica e híbrida de índio - e mais tarde de negro - na composição” (Freyre, 2003, p. 65). Por conseguinte, a

\footnotetext{
${ }^{1}$ É imprescindível ressaltar que a inserção da 'história e cultura africana e afro-brasileira' no currículo educacional brasileiro é consequência direta da resistência política dos movimentos negros (Silva, 2021). Um exemplo documentado é a carta aos dirigentes do país e a todos os membros da Assembleia Nacional Constituinte de 1987, resultado do Congresso Nacional do Negro pela Constituinte (CNN), realizado em agosto de 1986 na cidade de Brasília-DF (Silva, 2021), na qual já temos a defesa da inclusão obrigatória da 'História da África e da História do Negro no Brasil' nos currículos escolares (CNN, 1986). Ademais, a carta também defende que o dia 20 de novembro seja declarado o 'Dia Nacional da Consciência Negra' (CNN, 1986).
} 
formação da sociedade brasileira é baseada em uma miscigenação harmônica que, na verdade, segundo Freyre (2003), se constitui num processo de equilíbrio de antagonismos. E é esse tipo de formação social que implicará no mito da democracia racial, ressaltando que, a despeito dos antagonismos, a miscigenação corroborou a unidade nacional ou a reciprocidade cultural e econômica entre os extremos geográficos (Freyre, 2003).

Nesse sentido, conforme o pensamento freyreano, na conjuntura do Brasil, não podemos falar em racismo e desigualdade racial, tendo em vista que é uma sociedade equilibrada e harmônica. E mesmo no pensamento do antropólogo Darcy Ribeiro, figura importante nas pesquisas indigenistas na década de 50 e apoiador do resgate da memória de Zumbi dos Palmares, pode ser encontrado os resquícios da mesma esquizofrenia de Gilberto Freyre (Carvalho, 2003). Na sua obra clássica O povo brasileiro: a formação e o sentido do Brasil, Ribeiro (1995, p. 236) entende que a natureza do preconceito racial no Brasil, diferente do que se encontra em outros contextos sociais, o "[...] faz atuar antes como força integradora do que como mecanismo de segregação". Já o preconceito racial, de viés anglo-saxão, implica necessariamente segregação, fundamentado na hostilidade a todo tipo de convívio social (Ribeiro, 1995). Em contrapartida, "o preconceito de cor dos brasileiros, incidindo, diferencialmente, segundo a matiz da pele, tendendo a identificar como branco o mulato claro, conduz antes a uma expectativa de miscigenação" (Ribeiro, 1995, p. 236). Obviamente que, consoante Ribeiro (1995), essa expectativa é, decerto, discriminatória, tendo em vista a exigência de que os negros se submetam a um processo de branqueamento, assumindo o status quo branco, em lugar de aceitar a sua identidade racial. Mas, embora Ribeiro nomeie essa expectativa de discriminatória, ele a concebe como impulsora da integração, ainda que, para tanto, seja a própria negação da negritude identitária.

Por outro lado, pensadores como o sociólogo Florestan Fernandes e o antropólogo Kabengele Munanga asseveram que a miscigenação harmônica, por conseguinte, a ideia de democracia racial é, na verdade, um mito. Em seu livro O negro no mundo dos brancos, Fernandes (1972), analisando a situação do negro e do mulato na sociedade brasileira, a partir do contexto de São Paulo, assevera que a extrema desigualdade racial existente na cidade vem a ser mais genérica do que se supõe, ecoando-se em outras regiões do país. Destarte, a pesquisa de Fernandes (1972) evidenciou que a maior miscigenação e a maior visibilidade do negro e do mulato numa condição brasileirística de suposta tolerância "ideal", não implicavam transformações estruturais relevantes na participação racial. Mesmo porque, a sociedade brasileira, como propusera idilicamente Gilberto Freyre, não é o produto convergente e harmônico de três raças - portugueses, índios e africanos -, suplementadas pelos "mestiços". Desse modo, os povos indígenas ou africanos não tiveram a chance de compartilhar as vantagens e as experiências históricas dos colonizadores e seus descendentes, pois a sociedade colonial foi montada para o branco (Fernandes, 1972).

Consoante Fernandes (1972), a história brasileira é uma história do branco privilegiado para o branco privilegiado e, por essa razão, o negro foi exposto a uma estrutura social que se engendrou para as camadas privilegiadas da raça dominante. Dessa forma, "o negro permaneceu sempre condenado a um mundo que não se organizou para tratá-lo como ser humano e como 'igual”" (Fernandes, 1972, p. 15). Ao contrário, para se constituir partícipe desse mundo, o negro se viu constrangido a se identificar com o processo de branqueamento psicossocial e moral, abdicando de seus direitos e recebendo como dádiva a falta de solidariedade e condições para a igualdade racial e o exercício da cidadania (Fernandes, 1972). É como Fernandes (1972) asseverou tristemente: os negros tiveram que sair de sua própria pele, absorvendo e simulando o modus operandi do mundo dos brancos. Diante do exposto, conclui-se que "atrelado ao processo de miscigenação e à ideologia do 'branqueamento', esse mito racial não ameaçava acabar, apenas, com os conflitos raciais, mas com a própria existência do povo negro" (Silveira, 2020, p. 136-137).

Semelhantemente, o antropólogo Kabengele Munanga ratifica a linha de pensamento de Florestan Fernandes. Na sua obra Rediscutindo a mestiçagem no Brasil: identidade nacional versus identidade negra, Munanga (1999), tomando como aporte teórico a obra Nem preto nem branco, de Carl Degler, um importante estudo sobre a questão das relações raciais no Brasil e nos Estados Unidos, mostra que a diferença entre as relações raciais entre o Brasil e os Estados Unidos está no papel atribuído ao 
mulato. Na sociedade estadunidense, a ideologia racial obtemperou a concessão de lugar a uma pessoa intermediária no esquema biológico, em outras palavras, ou bem uma pessoa era negra ou branca (Munanga, 1999). No caso brasileiro, temos a complementação do mestiço à tríade "harmônica" - portugueses, índios e africanos. Nesse sentido, a ideia de mestiçagem no Brasil funciona como um mecanismo de aniquilação da identidade africana e afro-brasileira e, por conseguinte, de toda tentativa de implementação de políticas de ações afirmativas, que viabilizem uma maior acessibilidade da população negra a direitos como educação, saúde, moradia, trabalho, cultura e lazer.

Dessa forma, a ideia de mestiçagem está intrinsecamente associada ao processo de branqueamento no contexto brasileiro. A existência perversa e desumanizadora do branqueamento no Brasil, que corrobora o conceito de que o mulato possui um lugar "especial" na sociedade, tem como consequência a minoração do descontentamento entre as raças (Munanga, 1999). Por isso, no Brasil, o negro pode criar a expectativa de que seus filhos sejam capazes de transpor as barreiras que o mantiveram à margem da sociedade, se porventura eles se casem com gente mais clara (Munanga, 1999). Tal expectativa funciona como uma válvula de segurança sobre o descontentamento e frustração entre os negros e os mulatos (Munanga, 1999), fazendo com que se mantenham alienados diante da negação de seus direitos, implementada pelo Estado. Assim, negros e mulatos caíram na armadilha do branqueamento que não é um processo para todos, e abriram mão da formação de sua identidade de "excluídos" (Munanga, 1999) e, consequentemente, da luta por políticas de ações afirmativas.

Nesse aspecto, podemos asseverar que o mito da democracia racial foi a principal razão impeditiva, até 2001, para a formulação e efetiva implementação de ações afirmativas e políticas públicas antirracistas. Como bem salienta Munanga (2014, p. 37), "em função desse ideal, o Brasil conviveu muito tempo sem leis protecionistas dos direitos humanos dos não brancos, justamente porque não eram necessárias, em vista da ausência dos preconceitos e da discriminação racial”. E foi devido ao predomínio dessa consciência tranquila dos governantes e da sociedade civil organizada que inúmeras injustiças e violações dos direitos humanos foram cometidas contra negros e indígenas, como demonstram as pesquisas quantitativas que o IBGE e o IPEA realizaram nos últimos dez anos (Munanga, 2014).

É nesse contexto, que, segundo Jesus (2011), as inovações políticas representadas pelos resultados da Terceira Conferência Mundial de Durban serão um marco orientador das políticas multiculturais, com importância especial para as políticas de reconhecimento implementadas no contexto brasileiro. Assim, no Brasil pós Durban, tivemos a efetivação de algumas medidas de ações afirmativas para viabilizar a igualdade de oportunidades e minorar a questão da desigualdade racial e social enfrentada pela população negra.

\subsection{Ações afirmativas e o Brasil pós Durban: a presença e o lugar subalterno de docentes negros e negras na academia brasileira}

O Estatuto da Igualdade Racial, a Lei ${ }^{\circ} 12.288$, de 20 de julho de 2010, destinado a garantir à população negra a efetivação da igualdade de oportunidades, a defesa dos direitos étnicos individuais, coletivos e difusos e o combate à discriminação e às demais formas de intolerância étnica, em seu artigo 1 , § 1, inciso VI, assim define o que são ações afirmativas: “[...] os programas e medidas especiais adotados pelo Estado e pela iniciativa privada para a correção das desigualdades raciais e para a promoção da igualdade de oportunidades" (Brasil, 2010). Ou seja, as ações afirmativas visam a implementação de várias medidas, como, por exemplo, a lei de cotas, no enfrentamento das desigualdades raciais no tocante à educação, cultura, esporte e lazer, saúde, segurança, trabalho, moradia, meios de comunicação de massa, financiamentos públicos, acesso à terra, à justiça e outros (Brasil, 2010). Dessa forma, conforme o Estado, os programas de ações afirmativas constituir-se-ão em políticas públicas, que objetivam sempre reparar as distorções e desigualdades sociais e demais práticas discriminatórias adotadas, nas esferas pública e privada, durante o processo de formação social do Brasil (Brasil, 2010).

Como consequência da resistência política do movimento negro brasileiro e de algumas orientações da Declaração de 
Durban (2001), como a inserção da história e da contribuição dos africanos e afrodescendentes no currículo educacional, o Brasil, por meio da Lei $\mathrm{n}^{\circ} 10.639$, de 9 de janeiro de 2003, que altera a Lei $\mathrm{n}^{\circ}$ 9.394, de 20 de dezembro de 1996, estabelecerá a obrigatoriedade do ensino de "História e Cultura Afro-Brasileira" no currículo oficial da Rede de Ensino, dispondo em seu artigo 79-B, que "o calendário escolar incluirá o dia 20 de novembro como 'Dia da Consciência Negra"” (Brasil, 2003). Além disso, com base no Estatuto da Igualdade Racial, como parte da política de implementação de ações afirmativas, serão decretadas e sancionadas as leis de cotas $\mathrm{n}^{\mathrm{o}}$ 12.711/12 e 12.990/14, que, respectivamente, institui cotas raciais e sociais para o ingresso nas universidades e institutos federais (Brasil, 2012) e estabelece a reserva aos negros de $20 \%$ das vagas oferecidas nos concursos públicos para provimento de cargos efetivos e empregos públicos no âmbito da administração pública federal (Brasil, 2014).

Contudo, à despeito da implementação de ações afirmativas, como as leis de cotas, ainda persiste um problema no âmbito educacional brasileiro, que é a quase ausência de professores negros e negras nas universidades públicas. Ou seja, depois de alguns avanços, alcançado nos últimos dez anos, o mundo acadêmico brasileiro continua sendo um reduto majoritariamente branco e marcado pelas diretrizes do ethos branco. E esta quase ausência de professores negros e negras na academia brasileira não é fruto apenas de uma prática racista presente na sociedade, mas o resultado de um racismo acadêmico, ou seja, "[...] um esforço sistemático (mesmo que quase nunca verbalizado) feito pelos próprios acadêmicos” (Carvalho, 2003, p. 164).

Decerto, o mundo acadêmico brasileiro é uma pirâmide, na qual o topo pertence a uma elite branca, que, histórica e predominantemente, se colocou contrária à igualdade racial na docência superior. Em 2010, quando da discussão sobre políticas públicas e ações afirmativas, essa mesma elite se posicionou contra as políticas de ações afirmativas, sobretudo, na modalidade de cotas. E o enfrentamento aos obstáculos impostos por essa elite branca não foi realizado sem uma estratégia de resistência contínua e antirracista. Por isso, mesmo antes de 2010, a luta pela igualdade racial na educação superior só foi possível devido aos grupos diminutos de intelectuais negros e brancos que se engajaram na luta contra a desigualdade racial, por meio dos NEABs (Núcleos de Estudos Afro-Brasileiros), voltados para a temática racial (Gomes, 2005). E segundo Gomes (2005), a ação política e acadêmica desses grupos e núcleos, historicamente, tem sido fundamentais na luta em prol das ações afirmativas no Brasil, formulando e implementando medidas de acesso e permanência dos jovens negros nas universidades, bem como instigando o MEC no processo de formulação de propostas de ações afirmativas para a educação básica e superior.

É imprescindível salientar também que a elite branca naturalizou o processo de ingresso de novos professores nas universidades públicas, como se todos os docentes que hoje ensinam nas instituições federais tenham entrado por processos justos e transparentes, o que não é verdade (Carvalho, 2003). A própria história da academia brasileira no século XX atesta como esse tipo de processo seletivo barrou, propositadamente, o ingresso de ilustres intelectuais negros na universidade (Carvalho, 2003). Um dos casos mais conhecidos foi o de Guerreiro Ramos, um dos maiores sociólogos brasileiros do século XX, que se formou na primeira turma do curso de Filosofia da Universidade do Brasil, conhecida hoje como Universidade Federal do Rio de Janeiro - UFRJ (Carvalho, 2003). Porém, ele não foi incorporado ao corpo docente da UFRJ, assumindo em seu lugar um professor totalmente inexpressivo (Carvalho, 2003). Ramos desenvolveu toda a sua brilhante carreira acadêmica nos Estados Unidos (Carvalho, 2003), sendo professor da Universidade do Sul da Califórnia. E, no fim da vida, numa entrevista concedida a Lucia Lippi, denunciou que foi vítima de perseguição racial na atual UFRJ e não hesitou em asseverar que o Brasil é o país mais racista do mundo (Carvalho, 2003). O mesmo sucedeu com os brilhantes intelectuais negros Édson Carneiro, que foi "reprovado" no concurso para a cadeira de Antropologia da Universidade do Brasil, e Clóvis Moura, um dos maiores especialistas sobre a história da resistência negra no Brasil, que não encontrou lugar como professor em nenhuma das universidades públicas paulistas, dentre elas a renomada USP (Carvalho, 2003).

E partindo do arcabouço teórico do antropólogo José Jorge de Carvalho, professor da UnB e estudioso dessa questão da presença negra na docência superior brasileira, entendemos que este racismo acadêmico, além de impedir um maior ingresso de professores negros e negras nas universidades, possui dois aspectos nefastos: primeiro, limita a formação de novos quadros de 
professores e pesquisadores negros e negras; segundo, suplanta a referencialidade docente negra para a construção de uma autoimagem positiva por parte dos estudantes negros e negras, que tentam resistir aos embates do meio acadêmico branco e racista no qual tem que se mover (Carvalho, 2003).

Decerto, historicamente, somos cônscios de que a quantidade de docentes negros e negras no ensino superior é ínfima, basta realizar uma pesquisa simples em alguma instituição de ensino superior pública ou privada. E o racismo acadêmico é tão arraigado nas universidades brasileiras, que não temos, por parte dos órgãos oficiais como o INEP, CAPES ou CNPq, dados sistemáticos sobre a quantidade de professores e pesquisadores negros e negras nas universidades e instituições públicas e privadas, exceto em trabalhos acadêmicos, como o da pesquisadora Maria Solange Pereira Ribeiro (2001), que assinala, em sua tese de doutorado, haver, desde 1980, uma falta de ampliação da presença de professores negros e negras nas universidades públicas paulistas, sendo que em uma das universidades pesquisadas, dentre 2.000 professores, constatou-se apenas cinco professores negros. Em 2003, com o auxílio dos poucos docentes negros e negras de renomadas universidades públicas e privadas, Carvalho (2003, p. 167-168, grifo nosso) realizou um censo racial, destacando os seguintes dados estarrecedores:

Universidade de Brasília (UnB) - 1.500 professores - 15 professores negros; Universidade Federal de São Carlos (UFSCar) - 670 professores - 3 professores negros; Universidade Federal do Rio Grande do Sul (UFRGS) - 1.300 professores -3 negros (um deles é africano); Universidade Federal de Goiás (UFG) - 1.170 professores - 15 professores negros; Universidade Federal de Minas Gerais (UFMG) - 2.700 professores - 20 professores negros; Universidade Federal do Pará (UFPA) - 2.200 professores - 18 professores negros; Pontifícia Universidade Católica de Minas Gerais (PUC-MG) - 1.700 professores - 17 professores negros; Universidade Estadual do Rio de Janeiro (UERJ) - 2.300 professores -5 professores negros; Universidade Estadual de Campinas (UNICAMP) -1.761 professores -5 professores negros; Universidade de São Paulo (USP) - 4.705 professores - 20 professores negros; Universidade Federal do Rio de Janeiro (UFRJ) - 3.200 professores - 20 professores negros.

E no caso da USP, Carvalho (2003) constatou que dos 504 professores da Faculdade de Filosofia, Letras e Ciências Humanas (FFLCH), apenas três eram negros, sendo um deles africano, o eminente professor e antropólogo Kabengele Munanga. Em um artigo publicado em 2006, Carvalho apresentou novamente esse levantamento realizado por ele entre 1999 e 2003 para corroborar a sua denúncia e ilustrar a situação de confinamento racial dos professores negros e negras no mundo acadêmico branco do Brasil: na UnB, de 1.500 professores, apenas 15 eram negros; em universidades como a USP, UNICAMP, UFRJ e UFRGS, a proporção de professores negros não passava de $0,2 \%$; na UFSCar, de $0,5 \%$; na UFMG, de $0,7 \%$; juntando USP, UNICAMP, UFRJ, UFRGS, UFSCar, UnB e UFMG, tínhamos um contingente de aproximadamente 18.400 professores, sendo 18.300 brancos e 70 negros, ou seja, 99,6\% de docentes brancos e 0,4\% de docentes negros (Carvalho, 2006). Ademais, os estudos mais recentes, realizados por pesquisadores e pesquisadoras como Priscila Elisabete da Silva (2008), Ricardo Alexandre da Cruz (2009), Maria Auxiliadora de Paula Gonçalves Holanda (2009) e Mara Fernanda Chiari Pires (2014), atestam que o problema persiste, ou seja, o quadro de professores negros e negras nas universidades públicas brasileiras ainda é diminuto.

Esses dados demonstram que a elite acadêmica branca ainda se recusa a debater a questão da igualdade racial na docência do ensino superior. Em outras palavras, quando a discussão sobre a presença dos docentes negros e negras na academia é suscitada, essa elite reverbera o mito da democracia racial, declarando que o mundo acadêmico é um mundo sem cor, o antigo discurso colonial: "aqui ninguém tem cor, somos todos cientistas, pesquisadores, doutores, acadêmicos" (Carvalho, 2003, p. 172, grifo nosso). Ora, um mundo acadêmico sem cor, embora com poucos negros e majoritariamente branco.

Além do debate sobre a presença, outra questão suscitada é em relação ao lugar que os poucos professores negros e negras ocupam na estrutura administrativa da academia brasileira. É fato que os poucos docentes negros e negras encontram-se, na grande maioria dos casos, em posições subalternas, restando a eles apenas a sala - "senzala" - de aula. Mesmo porque, diferentemente dos professores brancos, um negro tem que provar para todos e a todo tempo a sua própria capacidade acadêmica. Em vista disso, nessa esfera de subalternidade, o negro é, de forma velada, impedido de ocupar certas funções gratificadas (FG) 
como coordenação de pesquisa, extensão ou pedagógica, e até mesmo cargos máximos de Direção (CD), como Diretor Geral, Pró-Reitor ou Reitor ${ }^{2}$.

Em um levantamento de dados, realizado em 2006, sobre o lugar dos professores negros e negras na estrutura administrativa universitária, Carvalho (2006) destacou que entre os mais de 1.000 reitores do conjunto de universidades públicas e privadas, apenas uma era negra, a reitora da Universidade do Estado da Bahia, sendo a primeira reitora negra da história do estado. Igualmente a UFMG já teve um reitor negro (Carvalho, 2006), porém, segundo Carvalho (2006, p. 94), os “[...] mais de 70 anos da USP, UFRGS, UFRJ e UFPR e de 45 anos da UnB não foram ainda suficientes para que um docente negro chegasse ao posto máximo dessas instituições de ensino superior". Na verdade, muitos professores negros e negras encerram a trajetória acadêmica, sem sequer ocuparem cargos mínimos de função gratificada (FG). É um verdadeiro confinamento racial (Carvalho, 2006).

\subsection{Resultados da pesquisa quantitativa sobre a presença e o lugar de professores negros e negras no IFMT}

Urge, ante o contexto anteriormente apresentado, suscitar algumas indagações:

\section{Questões de Pesquisa}

No contexto do Brasil pós Durban, o IFMT reverbera esse quadro de racismo acadêmico, que consiste na quase ausência de professores negros e negras nas estruturas didáticas e administrativas das universidades públicas e privadas? Reproduzindo o quadro descrito, qual é o lugar dos docentes negros e negras na estrutura educacional e administrativa do IFMT? E, por fim, quais são os avanços e desafios do IFMT no que concerne à política de ações afirmativas nesse cenário pós Durban? Para responder essas questões, apresentamos adiante a pesquisa quantitativa que fundamenta o estudo.

O quantitativo de total de professores por campus está elucidado no Quadro 1, onde se pode observar também a quantidade de questionários enviados e a quantidade de questionários respondidos, fazendo na última coluna a proporção referente à participação da pesquisa a cada campus.

Quadro 1. Quantitativo de total de professores por campus, seguido pela quantidade de questionários enviados e quantidade de questionários respondidos.

\begin{tabular}{|l|c|c|c|c|}
\hline Campus & Total & Enviados & Respondidos & \% \\
\hline IFMT campus Alta Floresta & 23 & 23 & 7 & $30,43 \%$ \\
\hline IFMT campus Cáceres & 61 & 49 & 8 & $13,11 \%$ \\
\hline IFMT campus Confresa & 50 & 44 & 17 & $34,00 \%$ \\
\hline IFMT campus Cuiabá Bela Vista & 65 & 62 & 10 & $15,38 \%$ \\
\hline $\begin{array}{l}\text { IFMT campus Cuiabá Octayde } \\
\text { Jorge Da Silva }\end{array}$ & 244 & 218 & 28 & $11,48 \%$ \\
\hline $\begin{array}{l}\text { IFMT campus Avançado de } \\
\text { Diamantino }\end{array}$ & 19 & 18 & 5 & $26,32 \%$ \\
\hline $\begin{array}{l}\text { IFMT campus Avançado de } \\
\text { Guarantã do Norte }\end{array}$ & 13 & 13 & 2 & $15,38 \%$ \\
\hline $\begin{array}{l}\text { IFMT campus Avançado de Lucas } \\
\text { do Rio Verde }\end{array}$ & 12 & 11 & 4 & $33,33 \%$ \\
\hline IFMT campus Rondonópolis & 47 & 44 & 10 & $21,28 \%$ \\
\hline IFMT campus São Vicente & 59 & 49 & 7 & $11,86 \%$ \\
\hline
\end{tabular}

\footnotetext{
${ }^{2}$ Quando da sanção da Lei no 11.892 de 2008, que criou os Institutos Federais de Educação, Ciência e Tecnologia, foram criados um quantitativo de cargos em comissão denominados de Cargos de Direção (CD) e determinadas Funções Gratificadas (FG), já comuns no âmbito das universidades federais.
} 
Research, Society and Development, v. 10, n. 17, e163101724511, 2021

(CC BY 4.0) | ISSN 2525-3409 | DOI: http://dx.doi.org/10.33448/rsd-v10i17.24511

\begin{tabular}{|l|c|c|c|c|}
\hline IFMT campus Avançado de Sinop & 15 & 12 & 2 & $13,33 \%$ \\
\hline IFMT campus Sorriso & 37 & 35 & 10 & $27,03 \%$ \\
\hline $\begin{array}{l}\text { Centro de Referência de Campo } \\
\text { Verde }\end{array}$ & 17 & 17 & 4 & $23,53 \%$ \\
\hline Centro de Referência de Jaciara & 10 & 10 & 5 & $50,00 \%$ \\
\hline $\begin{array}{l}\text { IFMT campus Avançado de } \\
\text { Tangará da Serra }\end{array}$ & 22 & 19 & 3 & $13,64 \%$ \\
\hline IFMT campus Várzea Grande & 25 & 24 & 4 & $16,00 \%$ \\
\hline \multicolumn{1}{|c|}{ Total } & $\mathbf{7 1 9}$ & $\mathbf{6 4 8}$ & $\mathbf{1 2 6}$ & $\mathbf{1 7 , 5 2 \%}$ \\
\hline
\end{tabular}

Fonte: Dados da pesquisa.

Observa-se que foram enviados 648 questionários, perfazendo 90,12\% do universo disponível. Os questionários não enviados foram constatados devido às mensagens de erro de retorno para o endereço eletrônico utilizado para enviá-los. Como os endereços eletrônicos são institucionais, somente há duas possibilidades, o endereço está correto e destinatário recebe a mensagem ou o endereço eletrônico está incorreto e o destinatário não recebe a mensagem, sendo excluída a possibilidade de a mensagem ser entregue a alguém que não seja seu destinatário. De todos os indivíduos disponíveis para a pesquisa, houve retorno em 125 questionários respondidos, o que corresponde à 17,52\% do total de questionários, sendo que esses questionários respondidos representam $22,13 \%$ dos professores que receberam o questionário. Essa diferença decorre do fato de alguns questionários terem sido enviados e o professor, por algum problema no endereço eletrônico, não os ter recebido.

Para uma melhor comparação da participação de professores pesquisados por campus, o Gráfico 1 elucida proporcionalmente essa participação, sendo o Centro de Referência de Jaciara, com 50\%, o maior participante proporcional da pesquisa. Já o IFMT campus Cuiabá Octayde Jorge da Silva, que foi onde mais se teve questionários respondidos, ao se fazer o mesmo comparativo proporcional estabelece a participação de 11,48\%. Assim, a instituição com maior frequência de respostas fica com o menor percentual em participação.

Gráfico 1. Comparativo proporcional por campus.

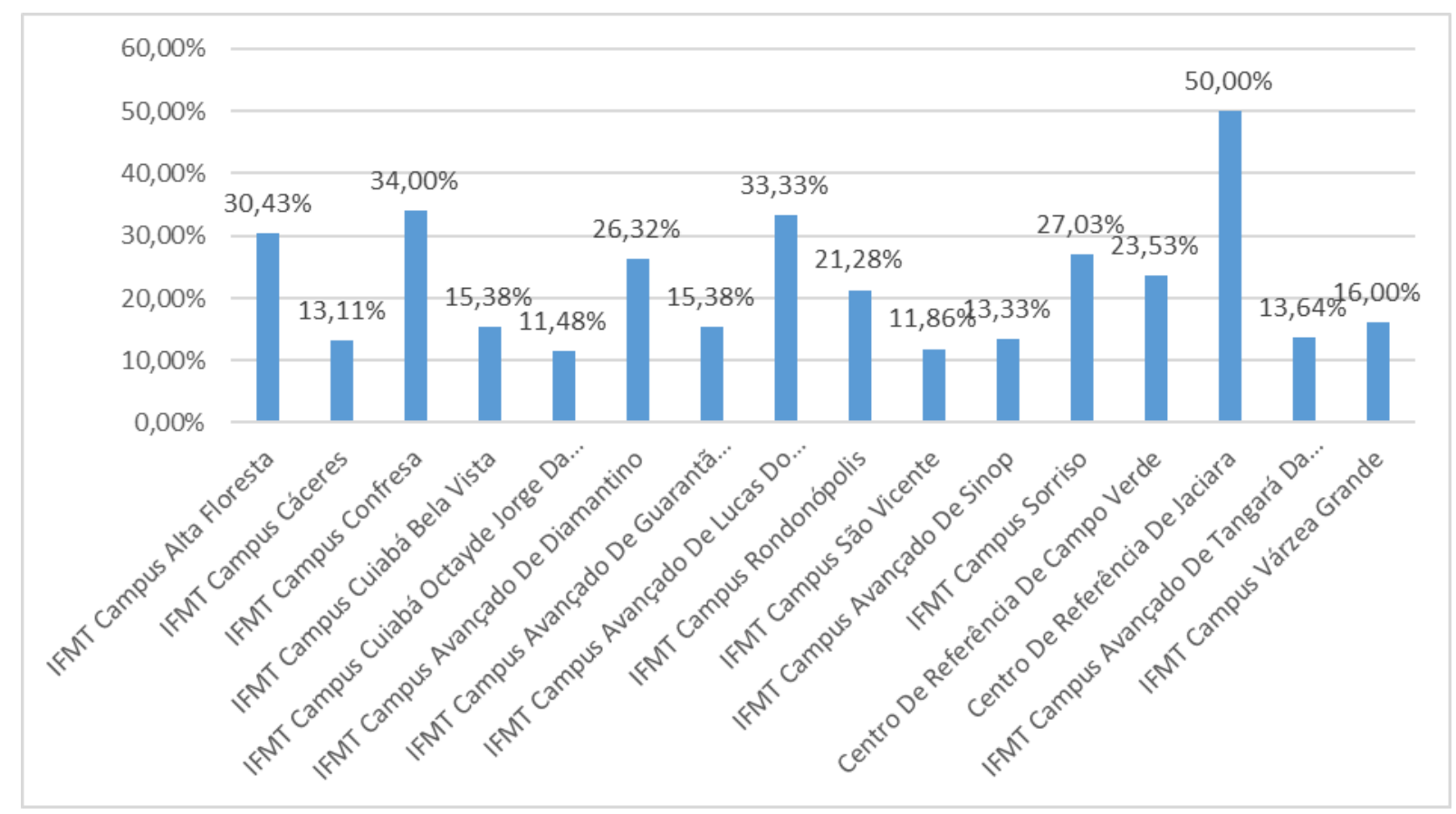

Fonte: Dados da pesquisa. 
No item 2 "Sexo: (_) Masculino / (_) Feminino” foi constatada a predominância masculina na instituição locus da pesquisa, onde o quantitativo era de 81 pessoas do sexo masculino, o que corresponde a 64,28\% dos pesquisados. Já no item 3 “Cor/Raça: (_) Amarelo/(_) Branco/(_) Indígena /(_) Pardo /(_) Preto” o resultado pode ser observado no Gráfico 2 a seguir, que apresenta o quantitativo de docentes pesquisados distribuídos por cor/raça.

Gráfico 2. Quantitativo de pesquisados distribuídos por cor/raça.

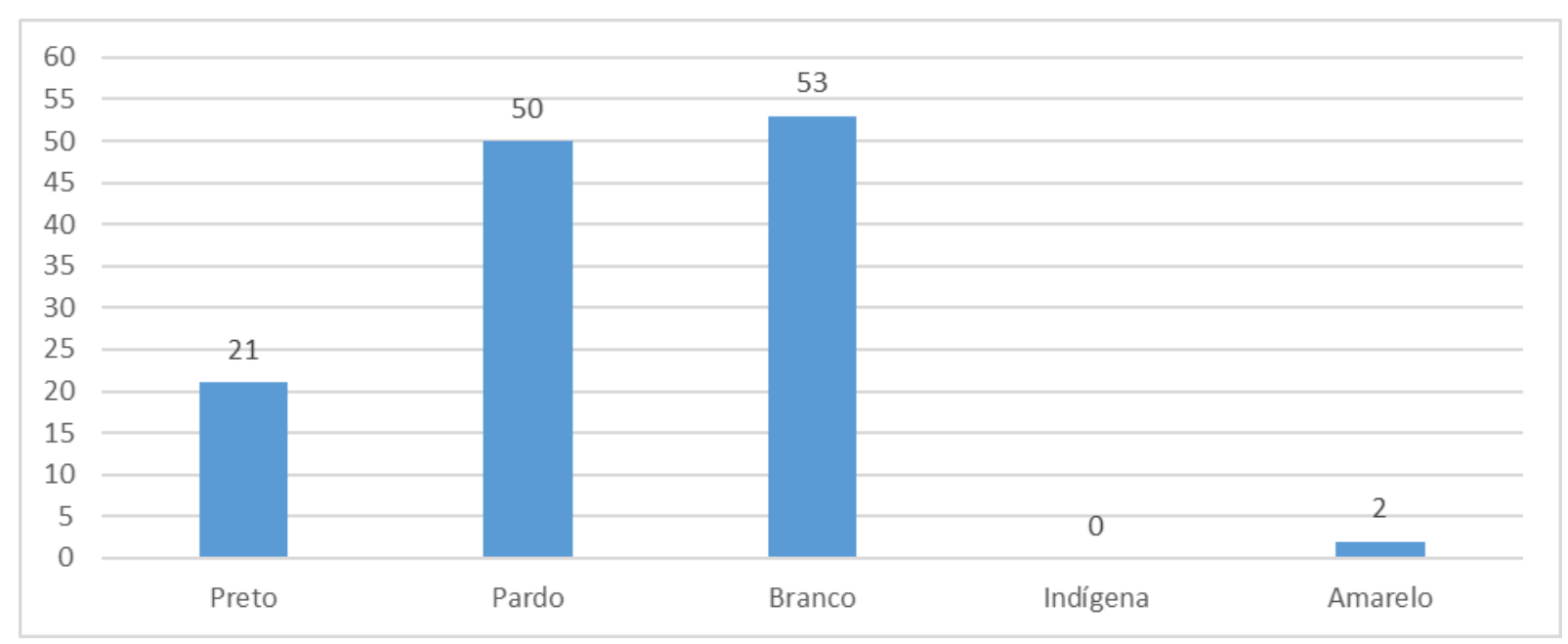

Fonte: Dados da pesquisa.

Para análise desse item, foram consideradas as definições dadas pelo Instituto Brasileiro de Geografia e Estatística (IBGE) que indica o grupo negros como sendo constituído por pretos e pardos. Assim, pode-se perceber que dentre os pesquisados, a maioria se considerou negra com representação de 56,35\% do total, seguido por 42,06\% que se declararam como brancos e somente $1,59 \%$ amarelos. Um destaque a ser considerado foi a não frequência de indígenas, visto que a instituição está instalada no Mato Grosso, estado que possui uma grande diversidade indígena.

Quanto o item 4 “Qual foi a forma de ingresso no IFMT? (_) Concurso público/Vaga para ampla concorrência /(_) Concurso público/Vaga reservada para negros / (_ Outros”, as frequências podem ser analisadas no Quadro 2, onde indicam uma ampla maioria de $92,85 \%$ com ingresso por meio de vagas para ampla concorrência e 4,76\% foi a representatividade de ingresso pelas vagas reservadas para negros. E determinadas pessoas indicaram outras formas de ingresso, sendo elas aproveitamento de concurso, concurso com vaga para deficientes e um por transferência.

Quadro 2. Modo de ingresso na instituição.

\begin{tabular}{|l|c|}
\hline \multicolumn{1}{|c|}{ Forma de Ingresso } & Quantidade \\
\hline Concurso público/Vaga para ampla concorrência & 117 \\
\hline Concurso público/Vaga reservada para negros & 6 \\
\hline Outro & 3 \\
\hline Total & $\mathbf{1 2 6}$ \\
\hline
\end{tabular}

Fonte: Dados da pesquisa.

Nesse mesmo item, ao fazer o cruzamento de informações entre a forma de ingresso e a quantidade de negros, percebese a intersecção desses dados no Quadro 3 logo abaixo, em que 9,68\% entraram pelas vagas reservadas para negros. 
Quadro 3. Comparativo de ingresso somente de negros.

\begin{tabular}{|l|c|}
\hline \multicolumn{1}{|c|}{ Forma de Ingresso de Negros } & Quantidade \\
\hline Concurso público/Vaga para ampla concorrência & 62 \\
\hline Concurso público/Vaga reservada para negros & 6 \\
\hline Outro & 0 \\
\hline \multicolumn{1}{|c|}{ Total } & $\mathbf{6 8}$ \\
\hline
\end{tabular}

Fonte: Dados da pesquisa.

No item 5 “Além da docência, ocupa cargo de Função Gratificada (FG) ou Cargo de Direção(CD)? (_) Sim /(_) Não”, como demonstram os dados no Quadro 4 que versa sobre os professores lotados nos campi com cargos de FG ou CD, obtivemos uma frequência de 36 professores que ocupam cargos que recebem FG ou CD, o que corresponde a 28,57\% dos pesquisados. Nesse item, há equilíbrio na divisão entre negros e brancos, havendo a mesma quantidade indicada.

Quadro 4. Professores lotados com cargos que recebem FG ou CD.

\begin{tabular}{|l|c|}
\hline \multicolumn{1}{|c|}{ Quantidade por Função Gratificada ou Direção } & Quantidade \\
\hline Preto & 9 \\
\hline Pardo & 9 \\
\hline Branco & 18 \\
\hline Indígena & 0 \\
\hline Amarelo & 0 \\
\hline \multicolumn{2}{r}{ Total } \\
\hline
\end{tabular}

Fonte: Dados da pesquisa.

Sobre o item 6 "Se no item anterior a resposta foi SIM, qual o cargo que ocupa?", as respostas foram as mais variadas, havendo 7 respostas em cargos que recebem CD, sendo 6 brancos e 1 pardo; os demais 29 são de FG, sendo 12 brancos, 8 pardos e 9 pretos.

Ao analisar o Gráfico 3, referente ao item 7 do questionário “Qual a maior titulação que possui? (_) Graduação /(_) Especialização /(_) Mestrado /(_) Doutorado /(_) Pós-Doutorado”, que trata da titularidade dos docentes distribuídos por cor/raça, pode-se perceber que 20 doutores são brancos, o que representa 64,52\% dos doutores pesquisados. Percebe-se também que os únicos 3 pós-doutorados são pardos. 
Gráfico 3. Quantitativo de titularidade distribuídos por cor/raça.

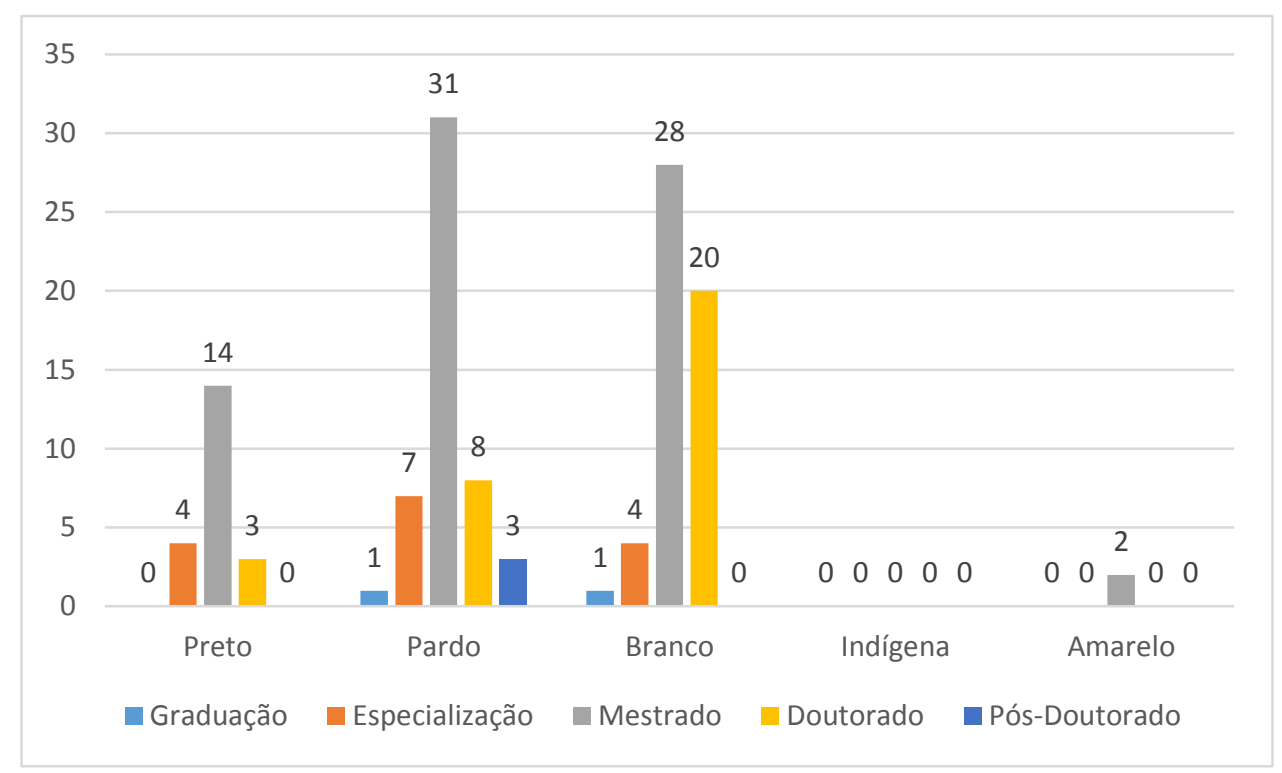

Fonte: Dados da pesquisa.

Ainda segundo o gráfico supracitado, percebe-se que há mais mestres pardos e pretos, que totalizam 45 e representam 60,00\% dos mestres pesquisados na instituição. Essas duas cores/raças também representam a maioria quanto à especialização, totalizando juntas 11 professores com representatividade de 73,33\% dentre todos os especialistas pesquisados.

\subsection{Discussão da pesquisa quantitativa sobre a presença e o lugar de professores negros e negras no IFMT: avanços e desafios}

O Instituto Federal de Mato Grosso nasceu no contexto da Lei n ${ }^{\circ} 11.892$, sancionada em 29 de dezembro de 2008, pelo então presidente Luiz Inácio Lula da Silva, que instituiu a Rede Federal de Educação Profissional, Científica e Tecnológica e, por conseguinte, criou os Institutos Federais de Educação, Ciência e Tecnologia. O IFMT foi instituído mediante a integração dos Centros Federais de Educação Tecnológica de Mato Grosso e de Cuiabá, e da Escola Agrotécnica Federal de Cáceres, tendo como sede da reitoria a cidade de Cuiabá (Brasil, 2008).

Em seu primeiro Plano de Desenvolvimento Institucional - PDI (2009-2014), documento no qual constam a missão, a visão, os valores do IFMT, bem como as políticas, metas e ações da instituição, não temos propostas de políticas ou metas institucionais para uma educação das relações étnico-raciais, mesmo sendo de conhecimento à época os marcos legais das Diretrizes Curriculares Nacionais para a Educação das Relações Étnico-Raciais e para o Ensino da História e Cultura AfroBrasileira e Africana, homologado em 18 de maio de 2004, por meio do Parecer 03/2004, de 10 de março, aprovado pelo Conselho Nacional de Educação (Brasil, 2004). Além disso, teremos em 2006 a apresentação do documento Orientações e Ações para a Educação das Relações Étnico-Raciais, publicado à época pela Secretaria de Educação Continuada, Alfabetização e Diversidade (SECAD) do Ministério da Educação, que trazia em sua estrutura argumentativa algumas sugestões de atividades, para o Ensino Médio, Educação de Jovens e Adultos, Licenciaturas, dentre outras. Contudo, é importante salientar que nem a Lei 10.639/2003 e tampouco o Parecer 03/2004 são citados no PDI de 2009, demonstrando assim que o IFMT principia enquanto instituição com propostas educacionais que, de alguma maneira, não favoreciam o cumprimento da Lei 10.639 e, portanto, uma educação para as relações étnico-raciais.

Foi somente no segundo PDI (2014-2018), no âmbito do projeto pedagógico institucional, que veremos uma discussão sobre respeito pela diversidade, direitos humanos e inclusão social. No capítulo III do PDI, que trata de políticas e metas para o ensino, tendo como aporte teórico a Declaração de Durban (2001), a Lei nº 10.639/2003, a Lei $n^{\circ} 11.645 / 2008$, que trata da 
obrigatoriedade do ensino "História e Cultura Afro-Brasileira e Indígena" no currículo oficial, e o Estatuto da Igualdade Racial, o IFMT, pela primeira vez, defende a necessidade de políticas educacionais e de ações afirmativas para as populações subrepresentadas (PDI, 2014). Para tanto, o IFMT estabeleceu algumas metas para as pró-reitorias e os campi, dentre elas:

[...] Fomentar o desenvolvimento de políticas, projetos e ações afirmativas em respeito às diversidades (sexual, de gênero, étnico-racial, religiosa, socioeconômica, etc.) e na busca da inclusão social e da igualdade. [...] Incentivar o desenvolvimento de tecnologias voltadas à inclusão e diversidade no âmbito do IFMT. [...] Fomentar Políticas de Ação Afirmativa para garantir o acesso e a permanência dos alunos em vulnerabilidade (PDI, 2014).

Com isso, o IFMT efetivamente propõe ações para combater a discriminação, o preconceito e a violência, embora com viés direcionado ao corpo discente do instituto.

No PDI (2019-2023), há um aprofundamento da discussão, já realizada no PDI de 2014, sobre o respeito pela diversidade, a promoção dos direitos humanos e as políticas de ações afirmativas para a promoção da igualdade étnico-racial. A novidade do PDI de 2019 está em incorporar políticas de qualificação para docentes e técnicos administrativos no escopo do texto, inclusive com informações estatísticas sobre o quantitativo de professores no IFMT, mas sem trazer os dados do marcador racial, o que dificulta a discussão de políticas de qualificação voltadas para os professores negros e negras da instituição. Ademais, não consta nesse PDI de 2019 a meta de um programa institucional de cotas para docentes negros e negras nos editais dos processos internos do Regulamento para Afastamento de Servidores em Atividades de Capacitação (RASAC) do IFMT, aprovado pela Resolução CONSUP / IFMT no 110/2016³ , que estabelece os critérios para o afastamento de servidores docentes e técnicos administrativos em educação para atividade de capacitação no Brasil ou no exterior.

Dito isso, percebe-se a partir dos dados estatísticos do nosso projeto de pesquisa, tomados aqui como um valor aproximado, que houve certos avanços no que concerne à presença de professores negros e negras na instituição, tendo em vista que $56,35 \%$ do total dos entrevistados se autodeclararam pretos ou pardos, seguido de 42,06\% de brancos e 1,59\% de amarelos. Isso demonstra que, de alguma maneira, há uma representatividade docente negra na instituição, embora somente um docente negro ocupe cargo máximo de Direção (CD). Nesse aspecto, os desafios se impõem para o IFMT e um deles é criar planos de ações afirmativas em matéria eleitoral para tornar viável a presença de candidatos negros e negras nas eleições para direção geral de campi e reitoria, no caso os espaços máximos de poder na instituição. Ademais, ficou patente na pesquisa que 64,52\% dos doutores entrevistados são brancos, o que torna necessária a implementação de ações afirmativas no âmbito dos editais do RASAC, delimitando no quantitativo de vagas por campi um percentual de cotas para docentes negros e negras que objetivam cursar mestrado ou doutorado no Brasil ou no exterior, ampliando assim o quadro de professores negros e negras com doutorado. Do mesmo modo ficou nítido na pesquisa a não frequência de docentes indígenas no IFMT, mesmo o estado de Mato Grosso possuindo grande diversidade indígena, por isso, é mister que a instituição amplie os projetos de pesquisa e extensão nas comunidades indígenas e, sobretudo, crie um projeto pedagógico específico de formação continuada de docentes indígenas, promovendo a igualdade de oportunidades para eles nos concursos públicos para professores do instituto. E, por fim, é fundamental que o IFMT aplique regularmente censos raciais e outros tipos de pesquisas quantitativas internas, criando, por conseguinte, um banco de dados permanente para melhor enfrentar as desigualdades raciais, sociais e de gênero e deste modo embasar a formulação e implementação de planos de ações afirmativas para os grupos sociais, historicamente, sub-representados e discriminados no mundo acadêmico, como os negros, os indígenas, a comunidade LGBTQIA+ e as mulheres.

\footnotetext{
${ }^{3}$ Atualmente esse documento é denominado de Regulamento da Política de Desenvolvimento de Pessoas (RPDP), aprovado pela Resolução CONSUP / IFMT nº 068/2021.
} 


\section{Considerações Finais}

No contexto geral do Brasil, nota-se que o enfrentamento desse problema dual, presença e lugar, requer medidas efetivas por parte do Estado, como também das próprias universidades. Por isso, objetivando combater a desigualdade racial no ambiente acadêmico, partimos do pressuposto de que somente as cotas na graduação e nos concursos não bastam para a ampliação do quadro de professores negros e negras na docência superior. É necessário que se amplie as ações afirmativas nos programas de pós-graduação, um sistema de preferência racial, possibilitando a formação de mais docentes negros e negras. Atualmente, universidades como UnB, UFG, UFMG, UFRJ, UFRGS, UNICAMP e USP, dentre outras, empregam cotas em determinados programas de pós-graduação. E mais, concomitantemente, entendemos ser necessário também que as próprias universidades públicas implementem medidas de ações afirmativas que promovam a igualdade de oportunidades para que seus poucos docentes negros e negras ocupem cargos de Direção (CD) ou funções gratificadas (FG), ampliando assim o debate sobre a questão da igualdade racial.

No caso específico do IFMT, os dados da nossa pesquisa destacam uma certa efetividade da presença de professores negros e negras na instituição. Contudo, tal efetividade não tem implicado em uma presença contundente desses docentes negros e negras em cargos de poder máximo como Cargo de Direção (CD), em outras palavras, a efetividade de presença não tem sido necessariamente efetividade de protagonismo negro nas instâncias de poder, o que demanda ações afirmativas no processo eleitoral para a direção geral dos campi e da reitoria, viabilizando candidaturas de servidores negros e negras para tais cargos. Além disso, conforme a pesquisa, há poucos docentes negros e negras com doutorado no instituto, o que demanda também ações afirmativas no âmbito da capacitação em pós-graduação para ampliar o percentual de professores negros e negras com grau de doutor. Portanto, é fundamental que o IFMT formule e implemente programas internos de ações afirmativas que abarquem os docentes negros e negras para que a efetividade de presença seja de fato efetividade de lugar.

Para tanto, sugerimos que o IFMT continue fomentando projetos que envolvam pesquisas quantitativas periódicas sobre a presença e o lugar dos docentes negros e negras e de outros grupos sociais discriminados, marginalizados e sub-representados com o intuito de fundamentar, estrategicamente, o enfrentamento da desigualdade racial na instituição.

\section{Agradecimentos}

Agradecemos ao IFMT e ao PIBIC-EM/CNPq pelo auxílio financeiro concedido a este projeto de pesquisa, que culminou no presente artigo.

\section{Referências}

Brasil. (2003). Lei $n^{\circ} 10.639$, de 9 de janeiro de 2003. Altera a Lei ${ }^{\circ}$ 9.394, de 20 de dezembro de 1996, que estabelece as diretrizes e bases da educação nacional, para incluir no currículo oficial da Rede de Ensino a obrigatoriedade da temática "História e Cultura Afro-Brasileira", e dá outras providências. Diário Oficial da União: Brasília, DF. http://www.planalto.gov.br/ccivil_03/leis/2003/L10639.htm.

Brasil. (2004). Parecer $C N E / C P n^{\circ} 3$, de 10 de março de 2004. Institui Diretrizes Curriculares Nacionais para a Educação das Relações Étnico-Raciais e para o Ensino de História e Cultura Afro-Brasileira e Africana. http://portal.mec.gov.br/dmdocuments/cnecp_003.pdf.

Brasil. (2006). Orientações e Ações para a Educação das Relações Étnico-Raciais. Brasília, DF: MEC/SECAD. http://portal.mec.gov.br/dmdocuments/orientacoes_etnicoraciais.pdf.

Brasil. (2008). Lei $n^{\circ} 11.645$, de 10 de março de 2008. Altera a Lei no 9.394, de 20 de dezembro de 1996, modificada pela Lei no 10.639, de 9 de janeiro de 2003, que estabelece as diretrizes e bases da educação nacional, para incluir no currículo oficial da rede de ensino a obrigatoriedade da temática "História e Cultura Afro-Brasileira e Indígena". http://www.planalto.gov.br/ccivil_03/_ato2007-2010/2008/lei/111645.htm.

Brasil. (2008). Lei $n^{\circ} 11.892$, de 29 de dezembro de 2008. Institui a Rede Federal de Educação Profissional, Científica e Tecnológica, cria os Institutos Federais de Educação, Ciência e Tecnologia, e dá outras providências. Diário Oficial da União: Brasília, DF. http://www.planalto.gov.br/ccivil_03/_ato20072010/2008/lei/111892.htm.

Brasil. (2010). Lei $n^{o}$ 12.288, de 20 de julho de 2010. Institui o Estatuto da Igualdade Racial. Diário Oficial da União: Brasília, DF. http://www.planalto.gov.br/ccivil_03/_Ato2007-2010/2010/Lei/L12288.htm. 
Brasil. (2012). Lei $n^{\circ} 12.711$, de 29 de agosto de 2012. Dispõe sobre o ingresso nas universidades federais e nas instituições federais de ensino técnico de nível médio e dá outras providências. Diário Oficial da União: Brasília, DF. http://www.planalto.gov.br/ccivil_03/_ato2011-2014/2012/lei/112711.htm.

Brasil. (2014). Lei $n^{\circ} 12.990$, de 9 de junho de 2014. Reserva aos negros $20 \%$ (vinte por cento) das vagas oferecidas nos concursos públicos para provimento de cargos efetivos e empregos públicos no âmbito da administração pública federal, das autarquias, das fundações públicas, das empresas públicas e das sociedades de economia mista controladas pela União. Diário Oficial da União: Brasília, DF. http://www.planalto.gov.br/ccivil_03/Ato2011-2014/2014/Lei/L12990.htm.

Carvalho, J. J. (2003). Ações afirmativas para negros na pós-graduação, nas bolsas de pesquisa e nos concursos para professores universitários como resposta ao racismo acadêmico. In: Silva, P. B. G.; Silvério, V. R. (Orgs.). Educação e ações afirmativas: entre a justiça simbólica e a injustiça econômica. Brasília: Instituto Nacional de Estudos e Pesquisas Educacionais Anísio Teixeira, 161-190.

Carvalho, J. J. (2006). O confinamento racial do mundo acadêmico brasileiro. Revista USP, 68, 88-103. https://www.revistas.usp.br/revusp/article/view/13485/15303.

Convenção Nacional do Negro pela Constituinte (CNN), Carta aos dirigentes do país e a todos os membros da Assembleia Nacional Constituinte - 87. (1986). Brasília, DF. https://pt.scribd.com/document/482909657/Convencao-Nacional-Do-Negro-Pela-Constituinte-1986.

Cruz, R. A. (2009). Negro e educação: as trajetórias e estratégias de dois professores da Faculdade de Direito de São Paulo nos séculos XIX e XX. (Dissertação de Mestrado, Pontifícia Universidade Católica de São Paulo, São Paulo, Brasil). https://repositorio.pucsp.br/jspui/handle/handle/10729.

Declaração e Programa de Ação adotados na III Conferência Mundial de Combate ao Racismo, Discriminação Racial, Xenofobia e Intolerância Correlata. (2001). Durban, África do Sul. https://www.oas.org/dil/port/2001\%20Declara\%C3\%A7\%C3\%A3o\%20e\%20Programa\%20de\%20A\%C3\%

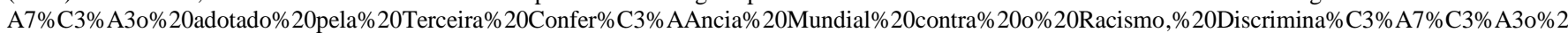
0Racial,\%20Xenofobia\%20e\%20Formas\%20Conexas\%20de\%20Intoler\%C3\%A2ncia.pdf.

Fernandes, F. (1972). O negro no mundo dos brancos. Difusão Europeia do Livro.

Freyre, G. (2003). Casa grande \& senzala: formação da família brasileira sob o regime da economia patriarcal. Global Editora.

Gomes, N. L. (2005). A universidade pública como direito dos(as) jovens negros(as): a experiência do Programa Ações Afirmativas na UFMG. In: SANTOS, S. A. (Org.). Ações afirmativas e combate ao racismo nas Américas. Brasília: Ministério da Educação, UNESCO, $245-262$.

Holanda, M. A. P. G. (2009). Tornar-se negro: trajetórias de vida de professores universitários no Ceará. (Tese de Doutorado, Universidade Federal do Ceará, Fortaleza, Brasil). http://www.repositorio.ufc.br/handle/riufc/3582.

Jesus, R. E. (2011). Ações afirmativas, educação e relações raciais: conservação, atualização ou reinvenção do Brasil?. (Tese de Doutorado, Universidade Federal de Minas Gerais, Belo Horizonte, Brasil). http://hdl.handle.net/1843/BUBD-92QPQK.

Marconi, M. A. \& Lakatos, E. M. (2002). Metodologia do trabalho científico. Editora Atlas.

Munanga, K. (1999). Rediscutindo a mestiçagem no Brasil: identidade nacional versus identidade negra. Vozes.

Munanga, K. (2014). A questão da diversidade e da política de reconhecimento das diferenças. Crítica e Sociedade - Revista de cultura política, 4(1), 34-45. http://www.seer.ufu.br/index.php/criticasociedade/article/view/26989/14725.

Pires, M. F. C. (2014). Docentes negros na universidade pública brasileira: docência e pesquisa como resistência e luta. (Tese de Doutorado, Universidade Estadual de Campinas, Campinas, Brasil). http://repositorio.unicamp.br/jspui/handle/REPOSIP/253910.

Plano de Desenvolvimento Institucional - PDI: 2009-2014 do Instituto Federal de Educação, Ciência e Tecnologia de Mato Grosso. (2009). Cuiabá, IFMT. https://ifmt.edu.br/media/filer_public/b8/b3/b8b305c8-5503-400b-b8d0-d3d4b7abe319/plano_desenvolvimento_institucional_2009-1.pdf.

Plano de Desenvolvimento Institucional - PDI: 2014-2018 do Instituto Federal de Educação, Ciência e Tecnologia de Mato Grosso. (2014). Cuiabá, IFMT. https://ifmt.edu.br/media/filer_public/b3/cb/b3cbb909-bb6d-48c7-abe8-d723d23dacc7/pdi-oficial-consup-ultima-versao1.pdf.

Plano de Desenvolvimento Institucional - PDI: 2019-2023 do Instituto Federal de Educação, Ciência e Tecnologia de Mato Grosso. (2019). Cuiabá, IFMT. https://ifmt.edu.br/media/filer_public/de/4d/de4dc553-4177-4878-b92c-473c88a9ed00/pdi_2019_2023_110p.pdf.

Ribeiro, D. (1995). O povo brasileiro: a formação e o sentido do Brasil. Companhia das Letras.

Ribeiro, M. S. P. (2001). O romper do silêncio: história e memória na trajetória escolar e profissional dos docentes afrodescendentes das Universidades Públicas do Estado de São Paulo. (Tese de Doutorado, Universidade de São Paulo, São Paulo, Brasil). https://www.teses.usp.br/teses/disponiveis/48/48133/tde03072003-154636/publico/TeseCompleta.pdf.

Sampieri, R. H., Collado, C. F. \& Lucio, P. B. (2013). Metodologia de pesquisa. McGraw-Hill.

Silva, J. M. (2021). O ‘não lugar’ epistemológico da Filosofia Africana nos livros didáticos de filosofia para o ensino médio aprovados pelo Programa Nacional do Livro e Material Didático - PNLD 2012. REFilo - Revista Digital de Ensino de Filosofia, 7, 1-21. https://periodicos.ufsm.br/refilo/article/view/61350/pdf.

Silva, P. E. (2008). Professor negro universitário: notas sobre a construção e manipulação da identidade étnico-racial em espaços socialmente valorizados. (Dissertação de Mestrado, Universidade Estadual Paulista, Araraquara, Brasil). https://repositorio.unesp.br/handle/11449/99011.

Silveira, P. H. F. (2020). Florestan Fernandes e a questão do negro: batalhas acadêmicas e políticas. Revista Estudos de Sociologia, 2 (26), 123-142. https://periodicos.ufpe.br/revistas/revsocio/article/view/249316.

Vieira, S. (2009). Como elaborar questionários. Editora Atlas. 